\title{
Long-term outcome of endometrial ablation therapy with Cavaterm Thermal Balloon in patients with abnormal uterine bleeding
}

\author{
(D) Mojgan Karimi-Zarchi1,2, (D) Marzieh Fathi ${ }^{3}$, (D) Afsar Tabatabaie ${ }^{2}$, (D Farimah Shamsi ${ }^{4}$, (D Leila Allahqoli1, \\ (D) Leila Zanbagh ${ }^{2}$, (D) Seyed Mohammad Amin Hashemipour ${ }^{5}$, (D Liselotte Mettler6 \\ 1Endometriosis Research Center, Iran University of Medical Sciences, Tehran, Iran \\ 2Department of Obstetrics and Gynecology, Shahid Sadoughi University of Medical Sciences, Yazd, Iran \\ ${ }^{3}$ General Practitioner Medicine, Shahid Sadoughi University of Medical Sciences, Yazd, Iran \\ ${ }^{4}$ Department of Epidemiology, Shahid Sadoughi University of Medical Sciences, Yazd, Iran \\ 5Department of Medical Teaching, Islamic Azad University Faculty of Medicine, Young Researchers and Elites Club, Yazd, Iran \\ 6Department of Obstetrics and Gynecology, Schleswig-Holstein University Hospital, Kiel, Germany
}

\section{Abstract}

Objective: The purpose of this study was to evaluate the long-term outcome of endometrial ablation (EA) therapy with Cavaterm Thermal Balloon in patients with abnormal uterine bleeding (AUB).

Material and Methods: The retrospective cross-sectional study was performed on 209 patients who referred to Shahid Sadoughi Hospital in Yazd, Iran between March 2010 and September 2017 with AUB undergoing EA therapy. The data was collected by a questionnaire from the medical records of patients and phone call. The primary and secondary outcomes post EA therapy (from six months to seven years postoperatively) were assessed in patients.

Results: The mean age of participants was $45.9 \pm 5.9$ years and the mean follow-up duration was $21.2 \pm 13.2$ months. The rate of treatment response was $95 \%$ in the first six months and $92.1 \%$ thereafter. The prevalence of amenorrhea was $41.2 \%$. The patient satisfaction rate at the end of follow-up duration was $81.3 \%$. Dysmenorrhea completely resolved in $32.6 \%$. Moreover, $1.4 \%$ of patients became pregnant during follow-up. By the end of follow-up, four (1.9\%) patients had a hysterectomy due directly to treatment failure.

Conclusion: This study showed that EA surgery with Cavaterm Thermal Balloon was an effective treatment for AUB. The procedure was safe and was associated with a very low rate of postoperative adverse events. The patient satisfaction rate was favorable. (J Turk Ger Gynecol Assoc 2020; $21: 1-9)$

Keywords: Abnormal uterine bleeding, endometrial ablation, hysterectomy, amenorrhea

Received: 10 June, 2019 Accepted: 09 September, 2019

\section{Introduction}

Abnormal uterine bleeding (AUB), which refers to any irregularity in the menstrual cycle, is one of the most common causes of women of childbearing age being referred to clinics (1). Approximately $16 \%$ of hysterectomies occur due to AUB (2). Hysterectomy is a definitive treatment for AUB and has been reported to be the second most common major surgical procedures in the United States (3). A strong preference for preservation of the uterus in developed countries has recently led to greater use of minimally invasive drug therapies, including Mirena intra-uterine device (also known as the levonorgestrel releasing device or LNG-IUS) and endometrial ablation (EA), 
even in cases where there is no desire for future pregnancy $(4,5)$. There is also a contraindication for drug therapies in cases with co-existing diseases such as diabetes and cardiovascular disease (6). EA therapy is preferred to hysterectomy due to the benefits of being outpatient based, being quicker, with fewer complications, any hospital stay is usually shorter and recovery is faster too (7). EA is performed using two methods: hysteroscopic endometrial ablation (HEA); and non-HEA (NHEA). HEA uses laser, electric current, or heat energy for coagulation or evaporation of the tissue. The NHEA approach is performed using EA computer systems with the aid of electric current, hyperthermia, cryotherapy or microwaves (8). The purpose of this study was to evaluate the long-term outcomes of EA therapy with the Cavaterm Thermal Balloon in patients with AUB.

\section{Material and Methods}

This was a retrospective cross-sectional study which was performed at Shahid Sadoughi Hospital in Yazd, Iran in 2018. All aspects of this research were approved by Ethics Committee of the Yazd Shahid Sahoughi University of Medical Sciences (IR. SSU.MEDICINE.REC.1396.186).

In this study, we reviewed medical record of 256 patients who had undergone EA between March 2010 and September 2017. These patients had been referred to Shahid Sadoughi Hospital with AUB, who did not respond to drug therapies or had an impediment to drug and surgical treatment or were reluctant to perform hysterectomy. All participants had completed informed consent before surgery.

Enrollment criteria were: 1) premenopausal women $\geq 18$ years old; 2) unwillingness to maintain fertility and no desire for pregnancy; 3) no urogenital infection; 4) natural history of cervical cytology; 5) negative Beta human choronionic gonadotropin test; 6) no contraindication for EA surgery; 7) underwent EA (Cavaterm Thermal Balloon) after March 2010; and 8) had documented follow-up $\geq 6$ months.

\section{Ablation procedure and follow-up}

Vaginal ultrasound was performed before surgery and the thickness of the myometrium, uterine cavity length and myometric length were measured. Endometrial curettage was then carried out to reduce endometrial thickness and the samples were sent for pathological examination. After placing an anesthetic mask, the patient was placed in a lithotomy position. The lower abdominal region, vulva, femoral region, and vaginal cavity were sterilized with iodine. The cervix was initially opened using a $6 \mathrm{~mm}$ dilator, followed by using a cavaterm system comprising a silicon balloon connected to a catheter with a width of $6 \mathrm{~mm}$ and a unit (thermal balloon EA device and catheter, Plus cavaterm TM model, (Veldana
Medical SA Co., Switzerland). The silicone balloon length was set based on the measurements of each individual uterine cavity. After emptying the air from the cavaterm system, the catheter end was inserted into the fundus, and the balloon was filled by glucose $5 \%$ fluid until the pressure reached $230 \pm 10$ $\mathrm{mmHg}$, and this pressure was maintained until the end of the treatment. Then, the circulation of fluid and heat was begun. EA started after reaching a temperature of $70 \pm 10^{\circ} \mathrm{C}$. The treatment was continued at this temperature for 10 minutes and then the heating was stopped, the fluid was pumped out and the catheter was removed. For removal the EA catheter was surrounded by an insulator to prevent thermal damage of the cervix and vaginal canal. The patient was then transferred to the recovery ward.

Patients were followed up for six to 90 months after EA therapy. In this study follow up period of patients was divided into four periods of up to six months, six to 12 months, twelve to 24 months and more than 24 months after surgery.

\section{Outcome measures}

The primary outcomes were changes in duration and interval of menstruation, amenorrhea rate, and bleeding reduction of at least $50 \%$ after surgery. It should be noted that amenorrhea rate and bleeding reduction of at least $50 \%$ six months after surgery were considered as the criterion for treatment response.

The secondary outcomes were the prevalence of anemia, dysmenorrhea, patient satisfaction, secondary intervention (medical or surgical) for recalcitrant AUB, adverse effect of EA therapy, and comparison variables in two groups of treatment respond and treatment failed. Anemia was defined if hemoglobin levels were lower than $12 \mathrm{mg} / \mathrm{dL}$ (9). Dysmenorrhea had been recorded using a 10-point visual analog scale in the medical record of patients, which higher points of three being considered as a dysmenorrhea (10), adverse effect of EA therapy including of blood discharge, fever (defined as body temperature of $>37.5{ }^{\circ} \mathrm{C}$ ), extreme and prolonged suprapubic pain, urinary tract infection, vaginosis, malodorous discharge, vomiting, and uterine rupture.

The primary and secondary outcomes of post EA therapy (from six months to seven years post- operatively) were assessed in patients.

Data collection was performed by means of a questionnaire and data was extracted from the medical records of the patients, telephone consultation with the patients.

\section{Statistical analysis}

The collected data were entered in the statistical software program IBM SPSS Statistics for Windows version 20.0 (SPSS Inc., Chicago, IL, USA). Descriptive statistics (mean \pm standard deviation, frequency, and percent) were used to present the data. Categorical variables were assessed with chi-squared 
and Fisher's exact test. Continuous variables were compared by Student's t-test. For all tests, p-values $<0.05$ indicated statistically significant differences.

\section{Results}

Of 256 existing medical records of patients with EA between March 2010 and September 2017, one patient was omitted due to hysterectomy during an initial examination. The reason of her hysterectomy was suspicion of endometrial cancer which proved to be metastatic sarcoma and was treated with radiotherapy after surgery. A further 17 patients had not attended a postoperative follow-up. Ten patients did not answer the phone call, and nineteen patients did not accept to participate in the study. Ultimately, the analysis was performed with the data of 209 patients.

The mean age of the patients was $45.94 \pm 5.9$ years. The reasons for undergoing EA were: desire to preserve the uterus and ovaries, and age conditions in 153 patients (73.2\%); and the presence of underlying disease as an obstacle to more invasive surgery, such as hysterectomy, in 56 patients (26.8\%). All patients had a chief complaint of excessive menstruation and a history of drug treatment. Most patients (75.1\%) had normal (proliferative or secretory) pathological results. Patient characteristics pre-EA surgery are presented in Table 1.

The result of primary outcomes in patients before and after EA surgery are presented in Table 2. The mean duration of menstruation was significantly decreased to $3.7 \pm 4.3$ days in the first six months $(p=0.001)$ and $3.1 \pm 3.3$ days 24 months after EA surgery $(p<0.001)$. The mean interval of menstruation cycle was significantly increased to $38.5 \pm 32.6$ days 24 months after EA surgery $(p=0.003)$.

Amenorrhea and bleeding reduction occurred in 193 (95\%) in the first six months and in 187 (92.1\%) after the first six months. At the end of follow-up, 84 (41.2\%) had amenorrhea (Figure 1). Preoperatively, 146 (69.9\%) patients had anemia before surgery and this proportion was significantly reduced after surgery to $61(29.2 \%)$ patients $(\mathrm{p}=0.001)$. Of 89 (44.1\% of the whole cohort) women who initially experienced dysmenorrhea, only 24 (11.5\%) reported that their symptoms had not changed or had worsened, a reduction of $32.6 \%$ (Table 3 ) while the other 65 women reported that their symptoms were "much improved" or "somewhat improved". A comparison of anemia and dysmenorrhea in patients before and after EA is shown in Table 3.

When patients were queried about overall satisfaction with the EA treatment $89.2 \%$ of them reported being either "very satisfied" or "satisfied" versus feeling "neutral" or expressed any degree of "dissatisfaction" (Table 4).

Following EA surgery 62 (29.7\%) patients had received secondary intervention for recalcitrant AUB until follow-up. Of that number 38 patients (18.8\%) required drug therapy, of which 29 responded (76.3\%), mostly to 20 or $40 \mathrm{mg}$ megestrol acetate per day. In addition, 24 (11.5\%) patients underwent

Table 1. Patient characteristics of the whole cohort $(n=209)$

\begin{tabular}{|c|c|c|c|}
\hline \multicolumn{2}{|l|}{ Variables } & Mean \pm SD & Minimum-maximum \\
\hline \multicolumn{2}{|l|}{ Age, years } & $45.94 \pm 5.9$ & $30-60$ \\
\hline \multicolumn{2}{|l|}{ Gravidity; $\mathrm{n}$} & $4.2 \pm 2.1$ & $1-14$ \\
\hline \multicolumn{2}{|l|}{ Parity, n } & $3.57 \pm 1.7$ & $1-12$ \\
\hline \multicolumn{2}{|l|}{ Weight, kg } & $73.73 \pm 9.9$ & $40-125$ \\
\hline \multicolumn{2}{|l|}{ Height, cm } & $158.2 \pm 5.3$ & $148-171$ \\
\hline \multicolumn{2}{|l|}{ BMI, $\mathrm{kg} / \mathrm{m}^{2}$} & $29.6 \pm 3.7$ & $17.8-48.2$ \\
\hline \multicolumn{2}{|c|}{ Bleeding per month before the EA surgery, day } & $12.1 \pm 5.7$ & $3-30$ \\
\hline \multicolumn{2}{|c|}{ Interval of menstrual cycles before EA surgery, day } & $15.9 \pm 7.4$ & $0-40$ \\
\hline \multirow{2}{*}{\multicolumn{2}{|c|}{ Follow-up duration, month }} & $21.2 \pm 13.2$ & $6-90$ \\
\hline & & $\mathbf{n}$ & $\%$ \\
\hline \multirow{6}{*}{ Diagnosis } & Normal (proliferative or secretory) & 157 & 75.1 \\
\hline & Simple endometrial hyperplasia & 15 & 7.2 \\
\hline & Complex endometrial hyperplasia & 2 & 1 \\
\hline & Myoma & 6 & 2.9 \\
\hline & Endometrial polyps & 21 & 10 \\
\hline & Adenomyosis & 8 & 3.8 \\
\hline \multicolumn{2}{|c|}{ Previous curettage } & 120 & 57.4 \\
\hline \multicolumn{2}{|c|}{ History of medical drug treatment for AUB } & 209 & 100 \\
\hline
\end{tabular}


hysterectomy following EA surgery, 23 of these were in the first three years after the EA procedure.

The most common adverse events after the surgery were blood discharge of more than 14 days in 182 (90.6\%) patients. Other adverse events included vaginosis, malodorous discharge, uterine rupture, extreme and prolonged suprapubic pain. The results of patient satisfaction, secondary intervention and adverse events after EA surgery are presented in Table 4.

Up to the end of the follow-up period, four (1.9\%) patients were treated by hysterectomy due to direct result of treatment failure [uterine perforation $(n=3)$, device dysfunction $(n=1)$ ] (Figure 2).

The mean age of patients in the treatment failure group was significantly higher than in the treatment response group ( 49.7 vs 41.2 years; $p=0.006$ ). In addition the uterus size $(p<0.001)$ tended to be significantly larger in the treatment failure group. There was no significant relationship between body mass index, gravidity, parity, intrauterine pressure and intrauterine temperature, and result of pathology with treatment failure. The results of comparison of variables in the treatment response and failure groups are presented in Table 5 .

The pathology result after surgery was reported to be normal endometrium (secretory or proliferative) in 157 patients (75.1\%). There was no significant relationship between the pathology type and the treatment response nor was there a significant relationship between the pathology type and the risk of future hysterectomy $(\mathrm{p}=0.084)$ (Figure 3$)$.

It is noteworthy that three (1.4\%) patients became pregnant in the follow-up period.

\section{Discussion}

In this retrospective study, the outcomes of EA therapy using Thermal Balloon and Plus CavatermTM technique were evaluated in 209 patients with AUB. Study results indicated duration of menstruation, a primary outcome, decreased significantly after treatment and the interval between menstrual cycles also increased significantly. These results are consistent with those of Asgari et al. (11) who reported the duration and

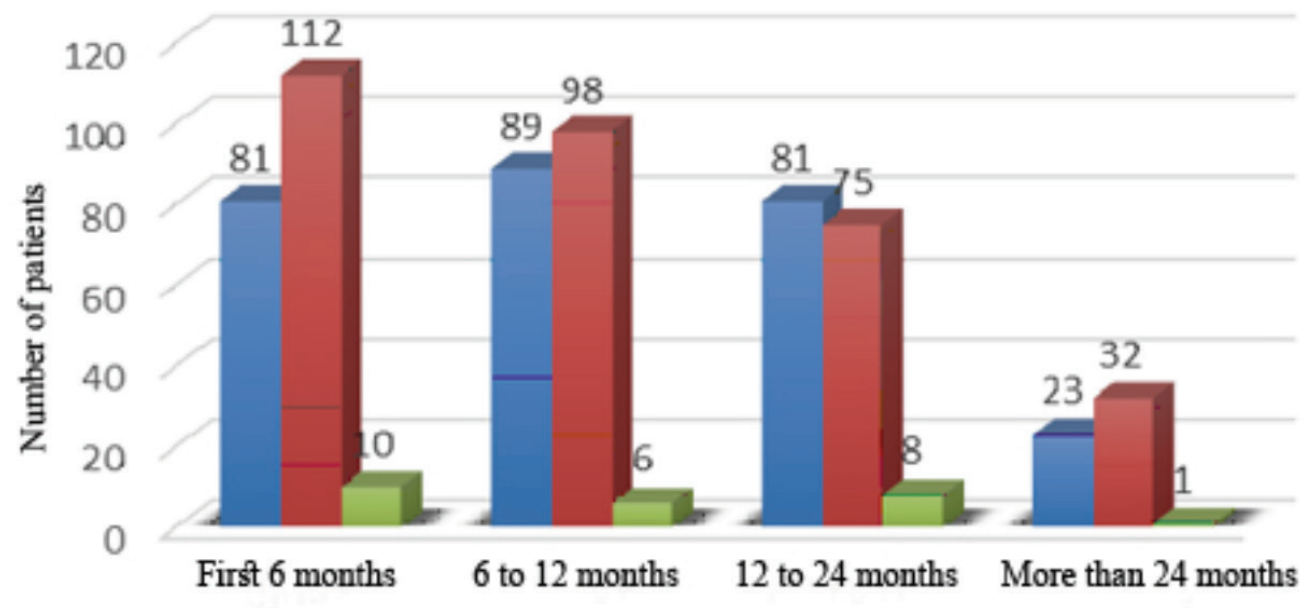

Amenorrhea

Bleeding reduction

Menorrhagia

Figure 1. Bleeding state of patients after endometrial ablation therapy

Table 2. Primary outcomes in patients before and after endometrial ablation surgery $(n=203 *)$

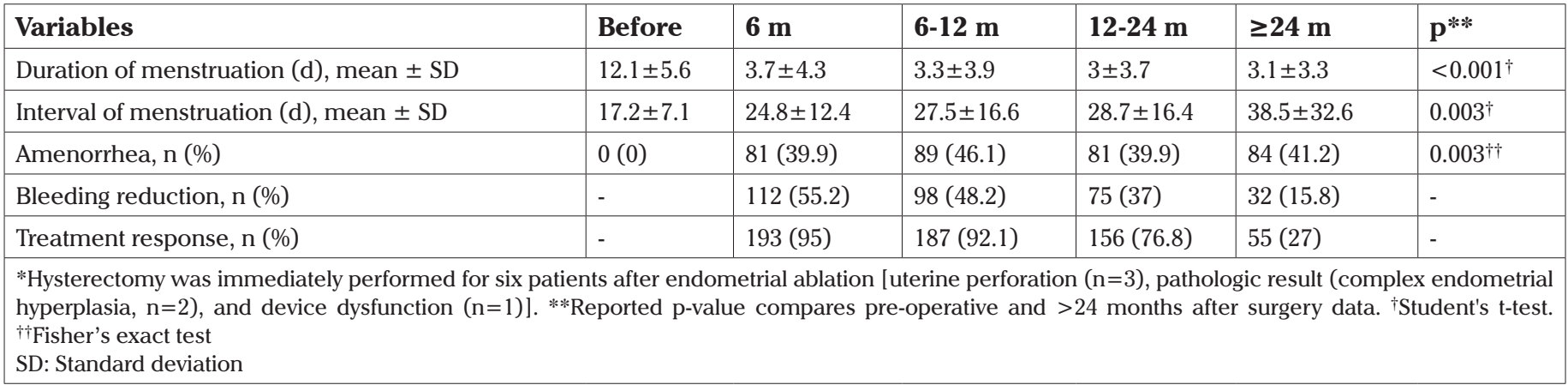


intervals of menstruation after EA was significantly decreased and increased respectively. In the Famuyide (12) study the menstrual bleeding rate in the patients with AUB treated with an EA method was reduced, which was associated with lower risk of hysterectomy in the future. In the present study, the rate of amenorrhea was $41.2 \%$ at the end of follow-up, which falls into the previously reported rate for amenorrhea, between 19.4 and $58 \%$, in studies of patients with AUB treated with an EA method (11,13-18).

In this study, the rates of treatment responses $\leq 6$ and $>6$ months were $95 \%$ and $92.1 \%$ respectively which are higher than that in the study of Sharma et al. (19) of $80 \%$ and $76 \%$ for the first six months and later, respectively. While some studies support the therapeutic role of EA $(13-16,19)$, unfortunately in some studies recurrent vaginal bleeding had occurred immediately or years after EA surgery (20-22). Although the recurrence of vaginal bleeding following EA is attributed to inadequate destruction of the endometrium $(20,21)$,

Table 3. The comparison of anemia and dysmenorrhea before and six months after endometrial ablation ablation $(\mathrm{n}=\mathbf{2 0 9})$

\begin{tabular}{|l|l|l|l|}
\hline Variable & Preoperative & Postoperative & p* \\
\hline Anemia, n (\%) & $146(69.9 \%)$ & $61(29.2 \%)$ & $<0.001$ \\
\hline Dysmenorrhea, n (\%) & $89(44.1 \%)$ & $24(11.5 \%)$ & $<0.001$ \\
\hline *Chi-squared test
\end{tabular}

Table 4. The result of patient satisfaction, secondary intervention and adverse events after endometrial ablation surgery $(n=209)$

\begin{tabular}{|c|c|c|}
\hline \multicolumn{2}{|l|}{ Variables } & Number (\%) \\
\hline \multirow{5}{*}{ Patient satisfaction } & Very satisfied & $170(81.3)$ \\
\hline & Satisfied & $11(5.25)$ \\
\hline & Neutral & $14(6.7)$ \\
\hline & Unsatisfied & $10(4.8)$ \\
\hline & Very unsatisfied & $4(1.9)$ \\
\hline \multirow{2}{*}{$\begin{array}{l}\text { Secondary } \\
\text { intervention for } \\
\text { recalcitrant AUB }\end{array}$} & Medical & $38(18.8)$ \\
\hline & Hysterectomy & $24(11.5)$ \\
\hline \multirow{8}{*}{ Adverse events } & Blood discharge & $182(90.6 \%)$ \\
\hline & Fever & $0(0)$ \\
\hline & $\begin{array}{l}\text { Extreme and prolonged } \\
\text { suprapubic pain }\end{array}$ & $1(0.5)$ \\
\hline & Urinary tract infection & $0(0)$ \\
\hline & Nausea & $0(0)$ \\
\hline & $\begin{array}{l}\text { Vaginosis, malodorous } \\
\text { discharge }\end{array}$ & $9(4.3)$ \\
\hline & Vomiting & $0(0)$ \\
\hline & Uterine rupture & $3(1.4)$ \\
\hline
\end{tabular}

unsuspected deep adenomyosis (22), and development of benign (myomas), or malignant diseases (endometrial hyperplasia, or cancer) may be responsible (23). Therefore, it is suggested that, despite EA rapid treatment response, patients need long follow-ups after surgery due to the risk of bleeding recurrence.

Most of the patients presented in this cohort were anemic before the EA surgery. Bernardi et al. (24) found that a significant percentage of women who report heavy menstrual bleeding are not only iron deficient, but also anemic, although most of their patients with anemia resolved after EA surgery. This was thought to be due to the high rates of amenorrhea and significant bleeding reduction as a result of EA (25). Kim et al. (26) suggested that EA is an effective alternative to hysterectomy for women with persistent menorrhagia and anemia when supportive measures fail.

Dysmenorrhea, defined as a complaint of pain experienced during or immediately before menstruation, improved in the majority of our patients after EA surgery, which is consistent with previous studies $(11,17,27)$. Prostaglandins (PG) and arachidonic acid metabolites play an important role in the pathogenesis of dysmenorrhea, being elevated in women with dysmenorrhea (28). However PGs, together with endothelin, which are powerful, vasoactive substances play a key role in the control of menstrual blood loss (28). Cameron et al. (29) showed the concentration of Prostaglandin E (PGE) and "total" PGs, defined by these authors as PGE + 6oxo PGF1 alpha + PGF2 alpha, was greater in the endometrium of those women with heavy menses than in those individuals with a normal menstrual loss. Therefore, it may be expected that dysmenorrhea will be improved by reducing menstrual bleeding.

The rate of patient satisfaction with treatment was high (86.6\%) in our study, consistent with other studies $(1,11-14,18,30)$. It has previously been reported that the resulting reduction in blood loss and increase in patient satisfaction rates leads to improved quality of life $(30,31)$.

In the present study, following EA surgery 24 (11.5\%) patients had subsequent hysterectomy. This is similar

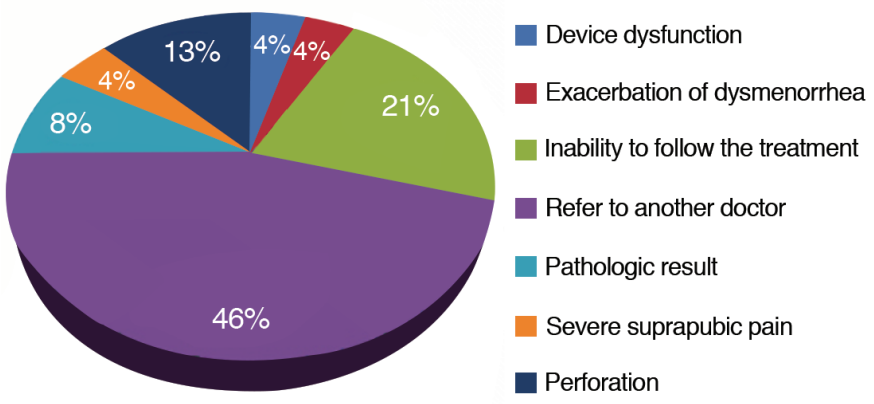

Figure 2. Causes of hysterectomy in patients 
to the rates of hysterectomy subsequent to EA therapy, from $10 \%$ to $13 \%$, which have been reported previously $(16,17,30,32-34)$ although higher rates (18\%-25\%) have been reported by some studies $(30,34)$. This variability in reported hysterectomy rates may be due to differences in study population and method or technique applied for EA therapy. For example Comino and Torrejón (34) reported an association between the presence of myoma and the need for subsequent hysterectomy.

Four (1.9\%) cases of hysterectomy resulted directly from treatment failure, one patient due to impaired function of the device and three others due to perforation of the uterus. One of these latter three patients required hysterectomy only four minutes after EA surgery due to the rupture of an arteriovenous malformation (AVM). Although AVM is a contraindication for EA, the 34-year-old patient desired uterine preservation and thus underwent EA therapy after giving informed consent for the hysterectomy, if required, so that the surgical team were prepared for the need for hysterectomy while undertaking the EA surgery. Rosati et al. (14) reported that of $5.2 \%$ of hysterectomies, $3.9 \%$ were directly due to treatment failure. Similarly, Comino and Torrejón (34) found that half of the $18 \%$ of hysterectomies occurring in their study were directly due to treatment failure. In our study, 95.8\% cases of hysterectomy were performed in the first three years subsequent to EA, the majority within the

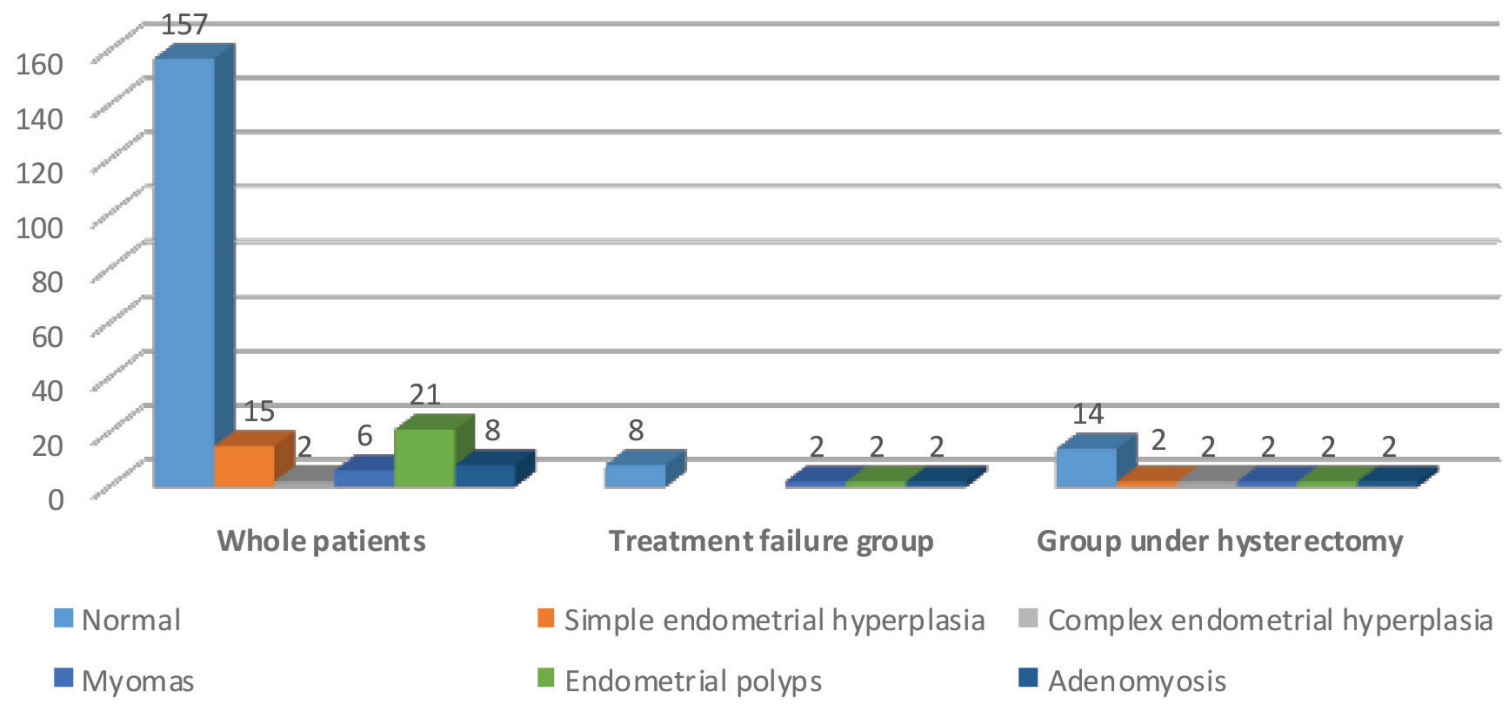

Figure 3. Results of pathology for patients

Table 5. Comparison of variables between treatment responders and treatment failure groups

\begin{tabular}{|c|c|c|c|c|}
\hline \multicolumn{2}{|l|}{ Variables } & $\begin{array}{l}\text { Treatment response } \\
\text { group }(n=195)\end{array}$ & $\begin{array}{l}\text { Treatment failure } \\
\text { group }(n=14)\end{array}$ & $\mathbf{p}$ \\
\hline \multicolumn{2}{|c|}{ Age (year); mean $\pm \mathrm{SD}$} & $41.2 \pm 5.8$ & $49.7 \pm 4.7$ & $0.006 *$ \\
\hline \multicolumn{2}{|c|}{ BMI $\left(\mathrm{kg} / \mathrm{m}^{2}\right) ;$ mean $\pm \mathrm{SD}$} & $29.6 \pm 3.7$ & $29.1 \pm 4.11$ & $0.591 *$ \\
\hline \multicolumn{2}{|c|}{ Parity; mean \pm SD } & $3.6 \pm 1.7$ & $3.2 \pm 1.1$ & $0.421 *$ \\
\hline \multicolumn{2}{|c|}{ Intrauterine pressure, $(\mathrm{mmHg}) ;$ mean $\pm \mathrm{SD}$} & $225.15 \pm 15.6$ & $226.1 \pm 15.9$ & $0.891 *$ \\
\hline \multicolumn{2}{|c|}{ Intrauterine temperature $\left({ }^{\circ} \mathrm{C}\right) ;$ mean $\pm \mathrm{SD}$} & $74.2 \pm 3.3$ & $73.35 \pm 4.1$ & $0.315^{*}$ \\
\hline \multirow{2}{*}{ Uterus size } & $<10 \mathrm{~cm}, \mathrm{n}(\%)$ & $131(67.2)$ & $2(14.3)$ & \multirow[t]{2}{*}{$<0.001 * *$} \\
\hline & $10-12 \mathrm{~cm}, \mathrm{n}(\%)$ & $64(32.8)$ & $12(85.7)$ & \\
\hline \multirow{6}{*}{ Results of pathology } & Normal (proliferative or secretory); n (\%) & $149(76.4)$ & $8(57.1)$ & \multirow[t]{6}{*}{$0.38 * * *$} \\
\hline & Simple endometrial hyperplasia; n (\%) & $15(7.7)$ & 0 & \\
\hline & Complex endometrial hyperplasia; n (\%) & $2(1)$ & 0 & \\
\hline & Myomas; n (\%) & $4(2.1)$ & $2(14.3)$ & \\
\hline & Endometrial polyps; n (\%) & $19(9.7)$ & $2(14.3)$ & \\
\hline & Adenomyosis; n (\%) & $6(3.1)$ & $2(14.3)$ & \\
\hline
\end{tabular}


6 months and 12 months, which is consistent with the results of Longinotti et al. (35) study.

In this study, the most frequent adverse events were blood discharge (90.6\%), vaginosis, malodorous discharge (4.3\%), uterine rupture (1.4\%), and extreme and prolonged suprapubic pain $(0.5 \%)$. These were not unexpected given previous research (11,32-34). A study audit of more than 10,000 EA surgery patients from the UK found an overall complication rate of $4.4 \%$. The most frequent complications were hemorrhage (2.4\%), uterine perforation $(1.5 \%)$ and cardiovascular and respiratory complications (0.5\%) (36). In the Gimpelson (37) study, the only complication was uterine perforation $(0.4 \%)$.

In the present study, the likelihood of a lack of treatment response and the risk of hysterectomy was higher in older patients, both of which can be related to the hormonal causes of AUB and is consistent with the literature $(17,19,38)$. Nakamura et al. (39) showed that age was associated with recurrence of menorrhagia and re-surgery. These authors also suggested that the EA surgery may be less effective for younger women with myomas, despite the longer period of time until the onset of menopause $(17,19,34,38)$.

The perioperative uterus size was greater than $10 \mathrm{~cm}$ in $85.7 \%$ of EA treatment non-responders and in $100 \%$ of perforation cases in our series. This suggests that uterine size may be an important criterion for selecting patients for EA to reduce the risk of treatment failure. Nakamura et al. (39) showed uterine cavity length $(\geq 10 \mathrm{~cm}$ ) was an independent risk factor for recurrence of menorrhagia and re-surgery. Larger uterine cavity length may be associated with more aggressive characteristics of myomas and thus it is not surprising that they are associated with an increased risk for recurrence and re-surgery (39). Furthermore, our series included six patients (42.85\%) with myomas, endometrial polyps, and adenomyosis who proved resistant to EA treatment. We found that EA tended to be less effective in this patient population, than in women with normal, simple and complex endometrial hyperplasia. Nakamura et al. (39) showed that EA was less effective in women with myomas and adenomyosis. This study suggested that the thickened myometrium in women with adenomyosis impaired the effectiveness of EA treatment and suggested that multiple rounds of EA treatment may more successfully control menorrhagia in cases with adenomyosis.

The incidence of pregnancy after EA surgery in our study was $1.4 \%$, in which two of three pregnancies were successful. In contrast Kohn et al. (40) reported that $85 \%$ of pregnancies following EA were terminated with abortion or due to ectopic pregnancy. This contradiction may simply be an effect of small sample size of this group in our study. It is important to make EA patients aware that EA surgery is not a contraceptive method and should apply reliable or permanent contraceptive techniques until menopause.

\section{Conclusion}

The results of this study showed that the EA surgery with Cavaterm Thermal Balloon was an effective treatment for AUB and had satisfactory results in terms of amenorrhea and treatment response levels. In addition, the patient satisfaction rate was favorable and the procedure is safe and is associated with a very low rate of postoperative adverse events. However, our findings indicate that EA surgery may be more effective for younger patients. Also, our findings indicate EA surgery may be less effective for women with myomas, endometrial polyps, adenomyosis and a larger uterus. Further research with larger sample sizes are needed to confirm which of these clinical parameters affects the success of EA surgery in AUB and may then be used to select the most appropriate patient groups for this type of treatment.

Acknowledgements: The authors wish to thank all the women who kindly agreed to participate in this study. We extend our special thanks to Shahid Sadoughi University of Medical Sciences for technical support of this research.

Ethics Committee Approval: All aspects of this research were approved by Ethics Committee of the Yazd Shahid Sahoughi University of Medical Sciences (IR.SSU.MEDICINE. REC.1396.186).

Informed Consent: All participants completed informed consent before surgery.

Peer-review: Externally peer-reviewed.

Author Contributions: Concept - M.K.Z., M.F., A.T., F.S., L.A., L.Z., S.M.A.H.; Design - M.K.Z., M.F., A.T., F.S., L.A., L.Z., S.M.A.H.; Data Collection or Processing - M.K.Z., M.F., A.T., F.S., L.A., L.Z., S.M.A.H.; Analysis or Interpretation - - M.K.Z., M.F., A.T., F.S., L.A., L.Z., S.M.A.H.; Literature Search - M.K.Z., M.F., A.T., F.S., L.A., L.Z., S.M.A.H., L.M.; Writing - M.K.Z., M.F., A.T., F.S., L.A., L.Z., S.M.A.H.

Conflict of Interest: The authors declare that they have no conflict of interest.

Financial Disclosure: This study was funded by Shahid Sadoughi University of Medical Science and Avicenna Research Institute, Tehran, Iran (grant number: 5522). 


\section{References}

1. Brun JL, Raynal J, Burlet G, Galand B, Quéreux C, Bernard P. Cavaterm thermal balloon endometrial ablation versus hysteroscopic endometrial resection to treat menorrhagia: the French, multicenter, randomized study. J Minim Invasive Gynecol 2006; 13: 424-30.

2. Penninx JP, Herman MC, Kruitwagen RF, Ter Haar AJ, Mol BW, Bongers MY. Bipolar versus balloon endometrial ablation in the office: a randomized controlled trial. Eur J Obstet Gynecol Reprod Biol 2016; 196: 52-6.

3. Wilcox LS, Koonin LM, Pokras R, Strauss LT, Xia Z, Peterson HB. Hysterectomy in the United States, 1988-1990. Obstet Gynecol 1994; 83: 549-55.

4. Matteson KA, Abed H, Wheeler TL 2nd, Sung VW, Rahn DD, Schaffer JI, et al. A systematic review comparing hysterectomy with less-invasive treatments for abnormal uterine bleeding. J Minim Invasive Gynecol 2012; 19: 13-28.

5. Karimi-Zarchi M, Dehghani-Firoozabadi R, Tabatabaie A, Dehghani-Firoozabadi Z, Teimoori S, Chiti Z, et al. A comparison of the effect of levonorgestrel IUD with oral medroxyprogesterone acetate on abnormal uterine bleeding with simple endometrial hyperplasia and fertility preservation. Clin Exp Obstet Gynecol 2013; 40: 421-4.

6. Fulop T, Rákóczi I, Barna I. NovaSure impedance controlled endometrial ablation: long-term follow-up results. J Minim Invasive Gynecol 2007; 14: 85-90.

7. Nagele F, Rubinger T, Magos A. Why do women choose endometrial ablation rather than hysterectomy? Fertil Steril 1998; 69: 1063-6.

8. Middleton LJ, Champaneria R, Daniels JP, Bhattacharya S, Cooper $\mathrm{KG}$, Hilken $\mathrm{NH}$, et al. Hysterectomy, endometrial destruction, and levonorgestrel releasing intrauterine system (Mirena) for heavy menstrual bleeding: systematic review and meta-analysis of data from individual patients. BMJ 2010; 341: 3929.

9. Blanc B. Nutritional anemias. Report of a WHO scientific group. WHO Tech Rep Ser 1968; 405: 1-40.

10. Larroy C. Comparing visual-analog and numeric scales for assessing menstrual pain. Behav Med 2002; 27: 179-81.

11. Asgari Z, Hoseinzadeh F, Hoseinzadeh A, Hafizi L. Evaluation of the success rate of endometrial ablation by cavaterm ${ }^{\mathrm{TM}}$ plus technique. J Minim Invasive Surg Sci 2014; 3: 12431.

12. Famuyide A. Endometrial sblation. J Minim Invasive Gynecol, 2018; 25: 299-307.

13. Harmon M, Kasbekar AV, Sinha A, Andrews V. Does the working temperature affect the outcome following microwave endometrial ablation? Ir J Med Sci 2017; 186: 399-401.

14. Rosati M, Vigone A, Capobianco F, Surico D, Amoruso E, Surico N. Long-term outcome of hysteroscopic endometrial ablation without endometrial preparation. Eur J Obstet Gynecol Reprod Biol 2008; 138: $222-5$

15. Mettler L. Long-term results in the treatment of menorrhagia and hypermenorrhea with a thermal balloon endometrial ablation technique. JSLS 2002; 6: 305-9.

16. Hokenstad AN, El-Nashar SA, Khan Z, Hopkins MR, Famuyide AO. Endometrial ablation in women with abnormal uterine bleeding related to ovulatory dysfunction: a cohort study. J Minim Invasive Gynecol 2015; 22: 1225-30.

17. Julian S, Habiba M. Factors affecting the outcome of endometrial ablation using Cavaterm ${ }^{\mathrm{TM}}$ plus. Eur J Obstet Gynecol Reprod Biol 2005; 123: 92-7.

18. Bouzari Z, Ganjoei TA, Yazdani S, Bijani A, Azimi S. Complications, bleeding and satisfaction of patients with abnormal uterine bleeding through the integration of endometrial degradation and thermal balloon therapy. Journal of Babol University of Medical Sciences 2015; 17: 22-7.

19. Sharma B, Preston J, Ray C. Microwave endometrial ablation for menorrhagia: outcome at 2 years-experience of a district general hospital. J Obstet Gynaecol 2004; 24: 916-9.

20. Turnbull L, Jumaa A, Bowsley SJ, Dhawan S, Horsman A, Killick SR. Magnetic resonance imaging of the uterus after endometrial resection. Br J Obstet Gynaecol 1997; 104: 934-8.

21. Lisa JR, Gioia JD, Rubin IC, Observations on the interstitial portion of the fallopian tube. Surg Gynecol Obstet 1954; 99: 159-69.

22. McCausland AM, McCausland VM. Depth of endometrial penetration in adenomyosis helps determine outcome of rollerball ablation. Am J Obstet Gynecol 1996; 174: 1786-94.

23. Wortman M, Daggett A, Deckman A. Ultrasound-guided reoperative hysteroscopy for managing global endometrial ablation failures. J Minim Invasive Gynecol 2014; 21: 238-44.

24. Bernardi LA, Ghant MS, Andrade C, Recht H, Marsh EE. The association between subjective assessment of menstrual bleeding and measures of iron deficiency anemia in premenopausal AfricanAmerican women: a cross-sectional study. BMC Womens Health 2016; 16: 50 .

25. Ryan TP. Using endometrial ablation as a treatment for abnormal bleeding: energy source comparisons and clinical results. Digital Optical Computing 2000: 10297.

26. Kim N, Donohue T, Sloand E, Stratton P. Successful use of balloon ablation to treat menorrhagia complicating aplastic anemia. Gynecol Obstet Invest 2008; 66: 123-6.

27. El-Toukhy T, Chandakas S, Grigoriadis T, Hill N, Erian J. Outcome of the first 220 cases of endometrial balloon ablation using Cavaterm ${ }^{\mathrm{TM}}$ plus. J Obstet Gynaecol 2004; 24: 680-3.

28. Coll Capdevila C. Dysfunctional uterine bleeding and dysmenorrhea. Eur J Contracept Reprod Health Care 1997; 2: 229-37.

29. Cameron IT, Leask R, Kelly RW, Baird DT. Endometrial prostaglandins in women with abnormal menstrual bleeding. Prostaglandins Leukot Med 1987; 29: 249-57.

30. Nikolaou M, Androutsopoulos G, Michail G, Papadopoulos V, Adonakis G, Decavalas G. Microwave endometrial ablation after endometrial curettage for the management of heavy menstrual bleeding. Clin Exp Obstet Gynecol 2015; 42: 469-72.

31. Hawe J, Abbott J, Hunter D, Phillips G, Garry R. A randomised controlled trial comparing the Cavaterm endometrial ablation system with the Nd: YAG laser for the treatment of dysfunctional uterine bleeding. BJOG 2003; 110: 350-7.

32. Penezic L, Riley K, Harkins G. Long-term patient satisfaction with thermal balloon ablation for abnormal uterine bleeding. JSLS 2014: 18. e2014.00325.

33. Comino R, Torrejón, Sánchez-Ortega I. Long-term results of endometrial ablation-resection. J Am Assoc Gynecol Laparosc 2002; 9: 268-71.

34. Comino R, Torrejón R. Hysterectomy after endometrial ablationresection. J Am Assoc Gynecol Laparosc 2004; 11: 495-9.

35. Longinotti MK, Jacobson GF, Hung YY, Learman LA. Probability of hysterectomy after endometrial ablation. Obstet Gynecol 2008; 112 : 1214-20.

36. Overton C, Hargreaves J, Maresh M. A national survey of the complications of endometrial destruction for menstrual disorders: the MISTLETOE study. Minimally Invasive Surgical TechniquesLaser, EndoThermal or Endoresection. Br J Obstet Gynaecol 1997; 104: 1351-9.

37. Gimpelson RJ. Ten-year literature review of global endometrial ablation with the NovaSure ${ }^{\circledR}$ device. Int J Womens Health 2014; 6: $269-80$. 
38. Soini T, Rantanen M, Paavonen J, Grénman S, Mäenpää J, Pukkala E, et al. Long-term follow-up after endometrial ablation in Finland: cancer risks and later hysterectomies. Obstet Gynecol 2017; 130: 554-60.

39. Nakamura K, Nakayama K, Sanuki K, Minamoto T, Ishibashi T, Sato E. Long-term outcomes of microwave endometrial ablation for treatment of patients with menorrhagia: A retrospective cohort study. Oncol Lett 2017; 14: 7783-90.

40. Kohn JR, Shamshirsaz AA, Popek E, Guan X, Belfort MA, Fox KA. Pregnancy after endometrial ablation: a systematic review. BJOG 2018; 125: 43-53. 